\title{
The Korean Geriatrics Society COVID-19 Strategy for Older Adults
}

\author{
Hyuk Ga ${ }^{1}$, Chang Won Won ${ }^{2}$, Eunju Lee ${ }^{3}$, Chang Oh Kim ${ }^{4}$, Il-Young Jang ${ }^{3,5}$, Hak Chul Jang ${ }^{6}$, Hang-Suk Cho ${ }^{7}$, Sun-wook Kim ${ }^{8}$ \\ ${ }^{1}$ Institute of Geriatric Medicine, Incheon Eun-Hye Hospital, Incheon, Korea \\ ${ }^{2}$ Elderly Frailty Research Center, Department of Family Medicine, Kyung Hee University School of Medicine, Seoul, Korea \\ ${ }^{3}$ Division of Geriatrics, Asan Medical Center, Seoul, Korea \\ ${ }^{4}$ Division of Geriatrics, Department of Internal Medicine, Yonsei University College of Medicine, Seoul, Korea \\ ${ }^{5}$ Pyeongchang Health Center \& Country Hospital, Gangwon-do, Korea \\ ${ }^{6}$ Department of Internal Medicine, Seoul National University Bundang Hospital and Seoul National University College of Medicine, Seongnam, Gyunggi-do, \\ Korea \\ ${ }^{7}$ Yonsei Noble Hospital, Seoul, Korea \\ ${ }^{8}$ Department of Hospital Medicine, Seoul National University Bundang Hospital, Seongnam, Gyunggi-do, Korea
}

As of May 16, 2020, the World Health Organization (WHO) reported a total of 4,434,653 confirmed cases of coronavirus disease 2019 (COVID-19) worldwide, including 302,169 COVID-19-related deaths. ${ }^{1)}$ Since the first case of COVID-19 was reported on January 20, 2020, Korea has extensively tested all contacts, with an emphasis on identifying individuals with respiratory illness, tracing, and testing for severe respiratory syndrome coronavirus 2 (SARS-CoV-2) that causes COVID-19. ${ }^{2)}$ Older adults are vulnerable to COVID-19; moreover, residents of long-term care facilities (LTCFs) are extremely frail, which is associated with high mortality. ${ }^{3-6)}$ One of the goals of establishing the Korean Geriatrics Society (KGS) is to make "Recommendations on healthcare for the aged to organizations and institutions." Accordingly, the authors representing the KGS composed a COVID-19 preventive strategy for older adults and posted it to the KGS website on March 13, 2020 (Table 1). ${ }^{8}$ The strategies employed the following principles: (1) two separate guidelines for older adults residing in community and LTCFs, respectively, reflecting the unique differences in their health conditions and environments; (2) strategies for LTCF health workers because their roles are crucial in LTCF infection control; (3) written in an easily comprehensible manner so that it can be clearly followed; (4) to follow general recommendations from international organizations such as the WHO and the Centers for Disease Control and Prevention (CDC), with modifications according to domestic policies as stipulated by the Korean Centers for Disease Control and Prevention (KCDC); and (5) to encourage indoor activities to prevent frailty, depression, and enhance resilience. ${ }^{9-11)}$

Our guidelines have some unique features. First, we included strategies for long-term care hospitals (LTCHs) among those for LTCFs. LTCHs are a wide-spread unique form of hospitals for frail and activities of daily living (ADL)-dependent older people in Korea; however, we assumed that the strategies for LTCHs are similar to those for LTCFs (nursing homes). ${ }^{12,13)}$ Second, we emphasized the importance of wearing facemasks regularly even in encounters with older adults or healthcare workers without respiratory symptoms, as $5 \%$ to $75 \%$ of positive cases are reportedly asymptomatic SARS-CoV-2 carriers. ${ }^{14)}$ Third, we divided the LTCF strategies into three parts; namely, blocking spread INTO, WITHIN, and BETWEEN facilities. In addition, the Korean Ministry of Health and Welfare issued a temporary regulation that permits telephone-based consultation and prescription and covers half of the expenses for COVID-19 testing for all new inpatients of LTCHs. ${ }^{11)}$

On May 2, 2020, the KCDC announced zero positive cases from randomly-screened samples from among 6,544 residents and care assistants of 46 LTCHs in the Seoul area. ${ }^{15)}$ However, new outbreaks have occurred since then and even tertiary transmission of COVID-19 has been reported in communities; ${ }^{16)}$ therefore, we believe our recommendations should be strictly followed until these conditions resolve, with revision of these guidelines as needed.

\section{ACKNOWLEDGMENTS}

\section{CONFLICT OF INTEREST}

The author claims no conflicts of interest. 
Table 1. Preventive strategies for coronavirus disease (COVID-19) infection in older adults

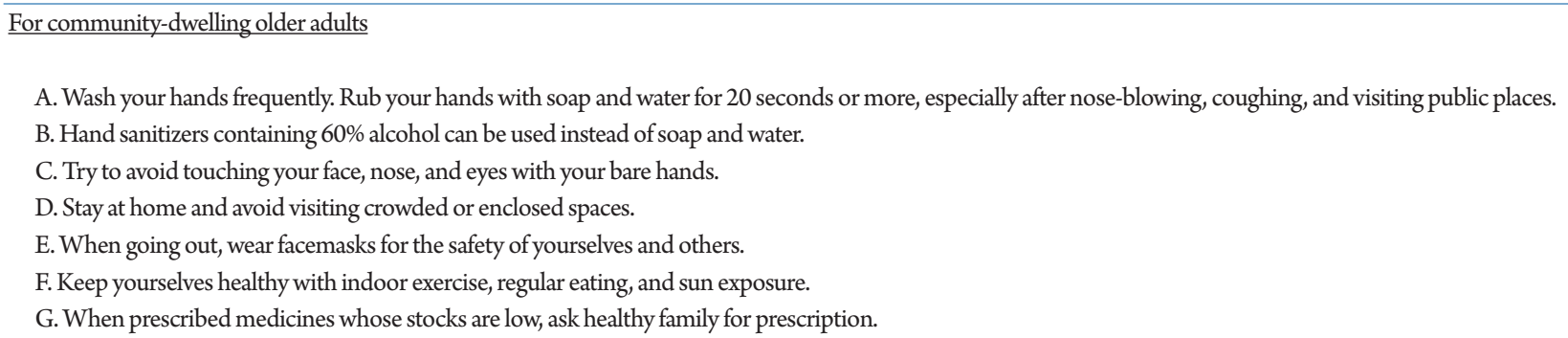

For residents and health-care workers in long-term care facilities

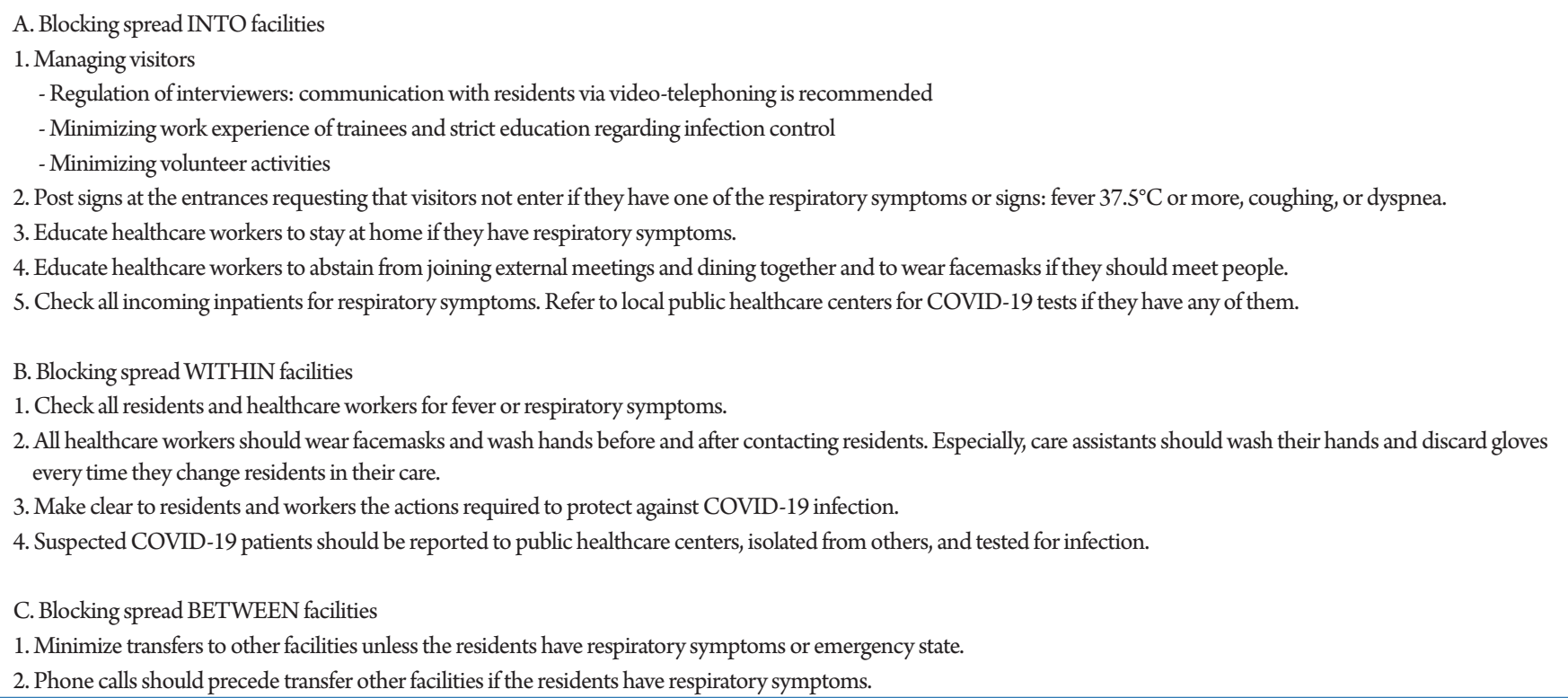

\section{REFERENCES}

1. World Health Organization. Coronavirus disease (COVID-2019) situation reports [Internet]. Geneva, Switzerland: World Health Organization; c2020 [cited 2020 May 31]. Available: https:// www.who.int/emergencies/diseases/novel-coronavirus-2019/ situation-reports.

2. Black JR, Bailey C, Przewrocka J, Dijkstra KK, Swanton C. COVID-19: the case for health-care worker screening to prevent hospital transmission. Lancet 2020;395:1418-20.

3. Na S, Cho Y, Lim TH, Kang H, Oh J, Ko BS. (2019). Risk factors and causes of short-term mortality after emergency department discharge in older patients: using nationwide health insurance claims data. Ann Geriatr Med Res 2019;23:133-40.

4. Kojima G. Prevalence of frailty in nursing homes: a systematic review and meta-analysis. J Am Med Dir Assoc 2015;16:940-5.

5. Ga H, Won CW, Jung HW. Use of the frailty index and FRAIL$\mathrm{NH}$ scale for the assessment of the frailty status of elderly individuals admitted in a long-term care hospital in Korea. Ann
Geriatr Med Res 2018;22:20-5.

6. Comas-Herrera A, Zalakain J, Litwin C, Hsu AT, Lane N, Fernandez JL. Mortality associated with COVID-19 outbreaks in care homes: early international evidence [Internet]. London, UK: International Long Term Care Policy Network; 2020 [cited 2020 May 31]. Available: https://ltccovid.org/2020/04/12/ mortality-associated-with-covid-19-outbreaks-in-care-homesearly-international-evidence/.

7. The Korean Geriatrics Society. History of the Korean Geriatrics Society [Internet]. Seoul, Korea: The Korean Geriatrics Society; c2014 [cited 2020 May 31]. Available from: http://www.geriatrics.or.kr/eng/organ/organ01.html.

8. The Korean Geriatrics Society. Preventive strategies for coronavirus disease (COVID-19) infection in older adults [Internet]. Seoul, Korea: The Korean Geriatrics Society; 2020 [cited 2020 May 31]. Available from: http://www.geriatrics.or.kr/board/list. html?num $=2215 \&$ start $=10 \&$ sort $=$ top $\% 20 \mathrm{desc}$,num $\% 20 \mathrm{de}-$ sc\&code $=$ notice \&key $=$ \&keyword $=$.

9. Centers for Disease Control and Prevention. Preparing for 
COVID-19 in Nursing Homes [Internet]. Atlanta, GA: Centers for Disease Control and Prevention; c2020 [cited 2020 May 31]. Available from: https://www.cdc.gov/coronavirus/2019-ncov/ hcp/long-term-care.html.

10. Korea Centers for Disease Control and Prevention. Maneuver for COVID-19 Combat for local government (version 7-1). Sejong: Korea Centers for Disease Control and Prevention; 2020.

11. Lim WS, Liang CK, Assantachai P, Auyeung TW, Kang L, Lee WJ, et al. COVID-19 and older people in Asia: AWGS calls to actions. Geriatr Gerontol Int 2020;May 4; [Epub]. http://doi. org/10.1111/ggi.13939.

12. Sanford AM, Orrell M, Tolson D, Abbatecola AM, Arai H, Bauer et al. An international definition for "nursing home". J Am Med Dir Assoc 2015; 16:181-4.

13. Ga H, Won CW. Perspective on long term care hospitals in Korea. J Am Med Dir Assoc 2013; 14:770-2.

14. Heneghan C, Brassey J, Jefferson T. COVID-19: What proportion are asymptomatic? [Internet]. Oxford, UK: Centre for Evidence-Based Medicine; c2020 [cited 2020 May 31]. Available from: https://www.cebm.net/covid-19/covid-19-what-propor- tion-are-asymptomatic/.

15. Lim S. 6544 samples from 46 long-term care hospitals in Seoul area were reported all negative [Internet]. Seoul, Korea: Medigate News; 2020 [cited 2020 May 31]. Available from: https:// www.medigatenews.com/news/1106529578.

16. Ock H. From Itaewon to Hongdae, coronavirus spread through karaoke rooms [Internet]. Seoul, Korea: The Korea Herald; 2020 [cited 2020 May 31]. Available from: http://www.koreaherald.com/view.php?ud $=20200515000724$.

Corresponding Author: Chang Won Won, Elderly Frailty Research Center Department of Family Medicine, Kyung Hee University School of Medicine, Kyungheedae-ro, Dongdaemun-gu, Seoul, Korea [02447]

Tel : +82-2-958-8700

Fax : +82-2-958-8699

E-mail: chunwon62@naver.com

ORCID: https://orcid.org/0000-0002-6429-4461

Received: May 19, 2020 ; Revised: May 26, 2020; Accepted: June 17, 2020 